\title{
FORUM
}

\section{Manned Space Flight Navigation Techniques}

\author{
from Captain P.V.H. Weems, U.s.N. (Ret.)
}

Major Richard C. Henry's paper (Journal, 16, 449) is timely. These comments are restricted to mid-course navigation and are intended to expand and clarify some parts of this excellent paper.

Major Henry divides space navigation into two parts, orbit and trajectory navigation: the first about one body, and the second, about two bodies. For example, Echo Satellite is in orbit about the Earth, while if its path were to include an orbit about the Moon as well as about the Earth, its path would be called trajectory. If we consider the path of a lunar capsule as determined by lunar perturbations of a body in orbit about the Earth, astronomers should be able to compute its trajectory, or path, or ephemeris, or orbit, and supply the information to the space navigator in the form of a Space Almanac. The guild of space navigators would use this shelf item, along with an accurate timepiece, and a marine type sextant, as the basic equipment for accomplishing mid-course navigation.

This will doubtless be, to the younger generation, an over-simplification of the problem. To old timers, air navigation was merely an extension of marine navigation methods, and some of them feel, as Major Henry inferred, that space navigation will, in practice, be a follow-on from air navigation. To carry this concept further, we will attempt to show the logic of this reasoning.

Without sophisticated computers, and with relatively crude timepieces, and angle-measuring equipment, Kepler computed planetary orbits or paths with almost miraculous accuracy. Isaac Newton designed the optical principle of the marine sextant which provides a simple, light, hand-held device for measuring an angle to within o! I, which is equivalent to 200 yards on the Earth's surface. Furthermore, this remarkable device, in space, can make good use of the smoothly-pivoted, semi-automatic control for the 'black box' sitting on the astronaut's shoulders! To carry this image further, John Harrison's original chronometer No. 4, now on loan by the British Government at the U.S. Naval Observatory, is still running and capable of providing Greenwich mean time to within half a second. In other words, Kepler, Newton and Harrison provided us with hand-held items capable of accomplishing mid-course space navigation today - and this at low cost, light weight, and easy to use.

To get back to Henry's orderly description, how can a timepiece, sextant and Almanac be used in space? Dr. J. G. Porter stated at the Agaard Seminar in 196I that the computations of satellite paths should be left to the 'guild of astronomers,' and that they will have trouble with close-in orbits due to extra perturbations. An example of these 'troubles' is the case where Simon Newcomb made 1200 corrections to the Moon's ephemeris, and this has been still further improved recently by Dr. Raymond Duncombe. 
Once the best possible reference path, orbit or trajectory is computed and furnished in the form of a Space Almanac to the space navigator, they will be in a position to make use of the timepiece and the sextant. In some respects, space navigation will be easier than sea or air navigation. The skill of the space navigator will be needed to detect, at the earliest possible moment, any divergence from the reference trajectory, and then to apply the needed small force in the proper manner and let it, by acceleration over as long a period as needed, keep his craft as close as possible to his 'course', which in effect is in the Almanac.

Consider a liner taking departure from Ambrose light, and equipped with a range finder, and a bearing compass which could supply accurate ranges and bearing across the Atlantic. The navigator would say he had it made! Using the centre of the Earth in the star field as a lighthouse, and the stadimetric distance from it as described by Major Henry, do we not have exactly the same situation? Of course, we are down to bare bones, and omit many details, yet the principles involved are quite clear. What we now need is some skilled space navigators. Doubtless, some tired space navigator will do the equivalent of 'reversing variation' and end up in perpetual orbit, yet it is certain that others will accomplish efficient space navigation and 'bring them back alive'.

The space navigator will doubtless be supplied with computers, slide rules, and other aids to navigation, but he should not attempt to turn into an electronic computer, but rather make full use of his own miraculous computer-the brain.

\section{The Binnacle at the Conn from Commander W. E. May, R.N.} (National Maritime Museum)

IT may be unexpected to some to find that among all the unsolved problems in the history of the magnetic compass there is a shortage of information on the form and arrangement of binnacles during the eighteenth and first part of the nineteenth centuries. The cupboard type of binnacle designed to take one or two steering compasses, according to the size of the ship, is pretty well documented for it is described in most of the books on navigation published in the French and English languages from the middle of the seventeenth century. There are also drawings in some books and there is a watercolour in the National Maritime Museum which shows the steering binnacle on the deck of His Majesty's Ship Deal Castle about 1775. This is however the only deck scene of the period known to me which does show a binnacle and very few binnacles appear in contemporary ship models.

It is with the second binnacle that the mystery really occurs. The early French writers tell us that a large ship had more than one binnacle but I do not find a 